Pease, P. (1957). J. gen. Microbiol. 17, 64-67

\title{
The Electron Microscopy of L-Forms Induced by Penicillin in Proteus vulgaris
}

\author{
By PHYLLIS PEASE \\ Department of Bacteriology, University of Birmingham
}

\begin{abstract}
SUMMARY: When cultivated on membranes for electron microscopy, in the presence of 800 units penicillin $/ \mathrm{ml}$. and $10 \%(\mathrm{v} / \mathrm{v})$ horse serum, a strain of Proteus vulgaris developed L-colonies in two stages. In the first cultures, the colonies consisted of naked protoplasts with a wide periphery of relatively disorganized protoplasm, and when further subcultured upon penicillin the entire colonies consisted of disorganized protoplasm. The typical bacillary form could be recovered by subculture of this material upon penicillin-free medium. In the process of regeneration the cultures passed initially through a stage in which they again consisted of protoplasts.
\end{abstract}

The mode of development of L-colonies has so far remained obscure. Klieneberger-Nobel (1949) suggested that the apparently structureless portion of the colony arises by coalescence of smaller units, whereas Dienes \& Weinberger (1950-51) considered that the mechanism in question is one of fragmentation rather than aggregation. Numerous more recent studies have done little to elucidate this problem, which has been rendered more difficult by the very great fragility of the L-colonies. In a previous study (Pease, 1956 a, $b$ ) this source of error was to some extent overcome by growing certain stages in Spirillum and Vibrio species, which strongly resembled L-forms, upon membranes for direct examination by the electron microscope. In the initial stages of this cycle the vibrios appeared to lose their customary curved regular outline and appeared in the form of irregular naked protoplasts, although each cell retained its single flagellum. From these protoplasts, small L-type colonies developed. Lederberg (1956) also noted the resemblance of the 'large bodies' to protoplasts.

Both the development from, and the reversion to the bacillary form, of more typical L-colonies induced in Proteus vulgaris under the influence of penicillin have now been observed by the same method, and it appears that both processes entail passage through a stage in which the bacteria grow in the form of naked protoplasts, without a firm cell wall.

\section{METHODS}

The strain of Proteus vulgaris used was a stock culture maintained in this laboratory. Cultures were made upon collodion membranes over nutrient agar plates containing 800 units penicillin $/ \mathrm{ml}$. and $10 \%(\mathrm{v} / \mathrm{v})$ horse serum. The technique used was that of Hillier, Knaysi \& Baker (1948; see also Pease, $1956 a$ ). Cultures were examined after $c .24 \mathrm{hr}$. of growth. 


\section{RESULTS}

When grown in the manner described, the entire culture consisted of typical L-colonies. The primary cultures upon penicillin-containing medium, when examined under the electron microscope, were seen to consist of groups of bodies of bacterial dimensions but oval or spherical in form and lacking the firmness of outline of normal bacteria. These bore a very strong resemblance to naked protoplasts. Surrounding these groups was a more diffuse zone of irregular material, consisting of larger and smaller granules (Pl. 1, figs. 1, 2).

When these primary L-cultures were further subcultured upon the medium containing penicillin and serum the appearance of the colonies under the electron microscope altered so that they appeared to consist entirely of the diffuse, irregular granular material (Pl. 1, fig. 3). All further subcultures on this medium retained this structure and form.

When subcultured on medium without added penicillin + serum, the early stages of the growth appeared to consist entirely of protoplast-like forms (Pl. 1, fig. 4). These protoplasts, which were in the process of regeneration towards the bacillary form, were firmer and fuller in appearance, and did not dry completely flat as did the degenerating states described already, but were in other respects similar. After a period ranging from 5 or $6 \mathrm{hr}$. to $24 \mathrm{hr}$. these protoplasts were transformed into vegetative bacilli. Further subcultures on medium without penicillin and serum consisted entirely of normal bacilli.

\section{DISCUSSION}

The phenomenon described in the foregoing section strongly resembles that which the apparently divergent hypotheses of Klieneberger-Nobel (1949) and of Dienes \& Weinberger (1950-51) are intended to explain. It appears as if the first stage in the formation of the $\mathrm{L}$-form from the normal vegetative organism is the loss of cell wall, leaving the protoplast. The second stage is a further disorganization of form and outline, presumably affecting the cell membrane, and resulting in a group of protoplasmic masses of irregular size and form. This is in accordance with the views of Dienes \& Weinberger, and serves to explain the nature of the larger bodies, the breakdown of which they observed, although some of their findings may refer to the larger and smaller protoplasmic masses. The formation and development of L-forms in Proteus which were observed by phase-contrast in the living state by Stempen \& Hutchinson (1951) bore a close resemblance to this suggested process. And the reversion from the L-form observed by the same technique by Medill \& Hutchinson (1954) showed a group of 'large bodies', similar to protoplasts in form and dimensions, each one of which grew into a normal bacterium by a direct process which is entirely compatible with the concept that the cell wall was in process of regeneration. The resemblance between the 'large bodies' of the L-form and protoplasts has been commented upon by Lederberg (1956), and in relation to penicillin-induced lysis, by Hahn \& Ciak (1957). This theory of the nature of $\mathrm{L}$-forms is, however, at variance with that supported by certain 
workers, notably Tulasne (1953 and numerous other papers), that the L-forms represent a specialized dwarf reproductive cycle in bacteria. If the findings of Gale (1947) and Gale \& Rodwell (1949) can be taken to indicate that the inhibitory action of penicillin is largely upon the cell envelopes of bacteria, then the loss or alteration of these structures may partially explain the relative resistance to penicillin of the L-form, especially since sensitivity appears to be restored or even enhanced immediately the bacillary form is resumed (Nermut, 1957). While this paper was in preparation, the same problem was discussed in an article by Park \& Strominger (1957). Although dealing mainly with the effect of penicillin upon cell-wall synthesis, these authors offer the same explanation for the penicillin resistance of the L-form.

\section{REFERENCES}

Dienes, L. \& Weinberger, H. J. (1950-51). The L-forms of bacteria. Bact. Rev. $15,245$.

Gale, E. F. (1947). The assimilation of amino-acids by bacteria. 1. The passage of certain amino-acids across the cell wall and their concentration in the internal environment of Streptococcus faecalis. J. gen. Microbiol. 1, 53.

Gale, E. F. \& Rodwell, A. W. (1949). The assimilation of amino-acids by bacteria. 7. The nature of resistance to penicillin in Staphylococcus aureus. J. gen. Microbiol. 3, 127.

Hahn, F. E. \& Ciak, J. (1957). Penicillin-induced lysis of Escherichia coli. Science, $125,119$.

Hillier, J., KNAYSI, G. \& Baker, R. F. (1948). New preparation techniques for the electron microscopy of bacteria. J. Bact. 56, 569 .

KLIENEBERGER-NobeL, E. (1949). Origin, development and significance of L-forms in bacterial cultures. J. gen. Microbiol. 3, 434.

Lederberg, J. (1956). Bacterial protoplasts induced by penicillin. Proc. nat. Acad. Sci., Wash. 42, 574.

Medild, M. A. \& Hutchinson, W. G. (1954). The reversion of the L form of Proteus mirabilis into the rod form. J. Bact. 68, 89.

Nermut, M. V. (1957). L forms of bacteria and their role in the origin of penicillin resistance. Nature, Lond. 179, 379.

PArk, J. T. \& Strominger, J. L. (1957). Mode of action of penicillin. Science, 125, 99.

Pease, P. (1956a). The gonidial stages in Spirillum spp. and Vibrio spp. J. gen. Microbiol. 14, 672.

Pease, P. (1956b). Electron microscopy of L-forms induced in Vibrio spp. by the action of penicillin. J. gen. Microbiol. 15, xiv.

Stempen, H. \& Hutchinson, W. G. (1951). The formation and development of large bodies in Proteus vulgaris OX-19. 1. Bright phase contrast observations of living bacteria. J. Bact. 61, 321.

Tulasne, R. (1953). Le cycle $L$ et les formes naines des bactéries. Symposium: Citologia Batterica. VIth Congr. int. Microbiol., Rome. 
Journal of General Microbiology, Vol. 17, No. 1
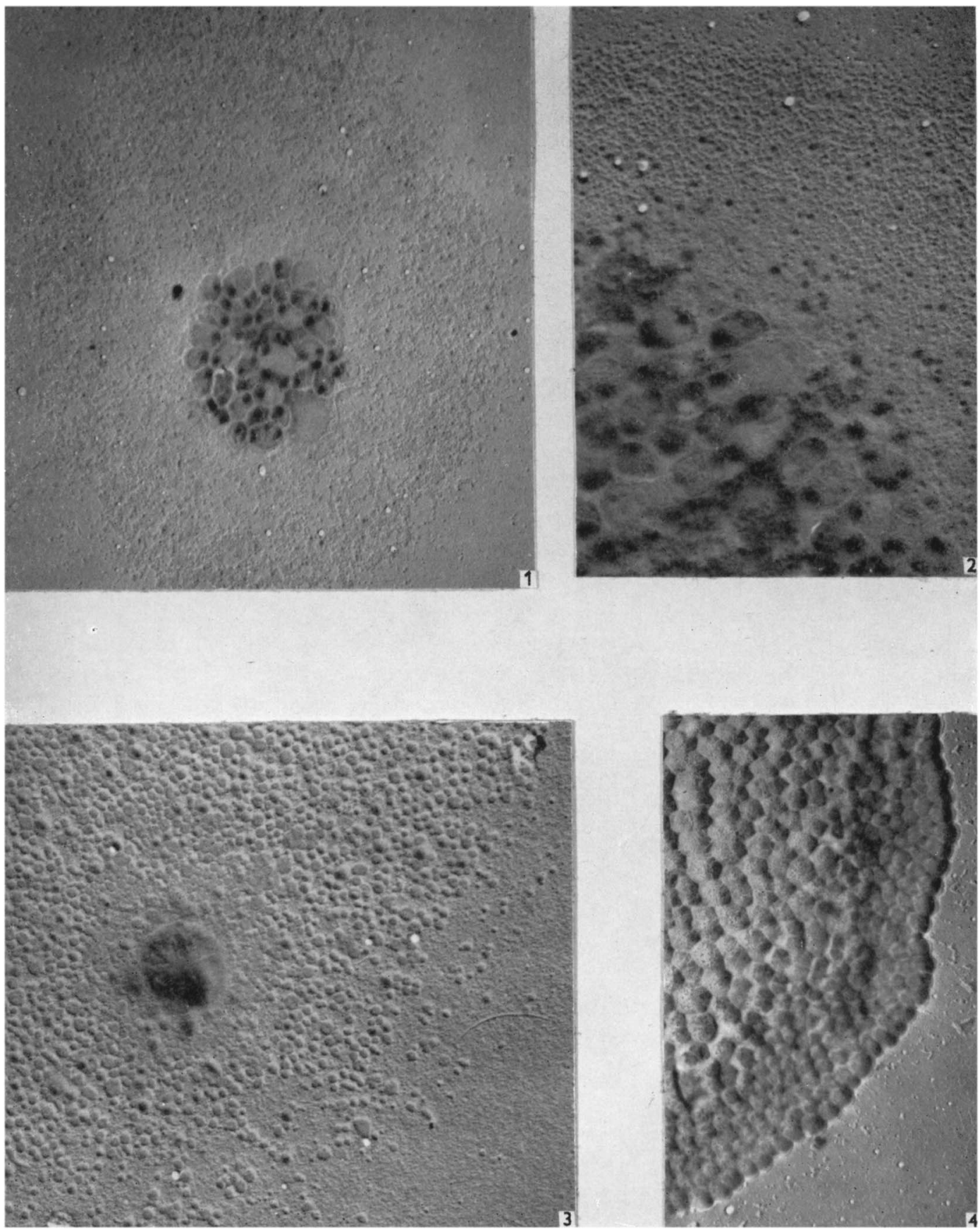

P. Pease-L-horms of Proteus. Plate 1

(Facing p. 67) 


\section{EXPLANATION OF PLATE}

Fig. 1. Proteus vulgaris L-colony, first subculture (24 hr.) on penicillin serum medium. Showing central group of degenerating protoplasts surrounded by diffuse matter. Electron micrograph, gold-palladium shadowed. $\times 5,000$.

Fig. 2. As fig. 1, sector of colony. $\times 10,000$.

Fig. 3. Second subculture $(24 \mathrm{hr}$.) on penicillin + serum medium. Diffuse matter mainly, with variously sized granules. Electron micrograph gold-palladium shadowed. $\times 15,000$.

Fig. 4. First subculture of L-forms upon medium without added penicillin and serum $(18 \mathrm{hr}$.$) . The colony consists entirely of protoplasts. These are fuller in appearance$ than those in the degenerating stages. Electron micrograph gold-palladium shadowed. $\times 4,000$.

(Received 14 January 1957) 